\title{
Effects of curcumin on artery blood gas index of rats with pulmonary fibrosis caused by paraquat poisoning and the expression of Smad 4, Smurf 2, interleukin-4 and interferon- $\gamma$
}

\author{
HONGGANG CHEN ${ }^{1}$, RONGJIA YANG ${ }^{1}$, YAN TANG ${ }^{2}$ and XIAOYAN FU ${ }^{3}$ \\ ${ }^{1}$ Department of Emergency, Gansu Provincial Hospital; ${ }^{2}$ Department of Emergency, \\ The Second People's Hospital of Lanzhou City; ${ }^{3}$ Department of Nursing, \\ The First Hospital of Lanzhou University, Lanzhou, Gansu 730000, P.R. China
}

Received October 30, 2018; Accepted February 21, 2019

DOI: $10.3892 / \mathrm{etm} .2019 .7341$

\begin{abstract}
Effects of curcumin on artery blood gas index of rats with pulmonary fibrosis caused by paraquat poisoning and the expression of Mothers against decapentaplegic homolog 4 (Smad4), Smad ubiquitination regulatory factor 2 (Smurf2), interleukin-4 (IL-4) and interferon- $\gamma($ IFN- $\gamma)$ were explored. A total of 54 Wistar rats were randomly selected, of which 36 rats were selected for paraquat poisoning pulmonary fibrosis modeling, and 18 were used in the control group for normal feeding. Then, 18 rats were randomly selected from the modeled groups and injected with curcumin and classified as the curcumin group. The remaining 18 rats were not processed and 17 were successfully modeled as the paraquat group. The expression of SMAD4, Smurf2, IL-4 and INF- $\gamma$ was detected by enzyme-linked immunosorbent assay. Abdominal aortic blood was taken for determination of $\mathrm{pH}$, arterial partial pressure of oxygen $\left(\mathrm{PaO}_{2}\right)$ and arterial partial pressure of carbon dioxide $\left(\mathrm{PaCO}_{2}\right)$. The artery blood $\mathrm{PaO}_{2}$ and serum INF- $\gamma$ of the curcumin and paraquat groups were significantly higher on day 1 than those on day $5(\mathrm{P}<0.05)$. The artery blood $\mathrm{PaO}_{2}$ and serum INF- $\gamma$ in the curcumin group were higher than those in the paraquat group $(\mathrm{P}<0.05)$. The artery blood $\mathrm{PaCO}_{2}$, serum Smad4, Smurf2 and IL-4 in the curcumin group were significantly lower on day 1 than those on day 5 $(\mathrm{P}<0.05)$. The artery blood $\mathrm{PaCO}_{2}$, serum Smad4, Smurf2 and IL-4 in the paraquat group were significantly lower on day 1 than those on day $5(\mathrm{P}<0.05)$. The $\mathrm{PaCO}_{2}$, serum Smad4, Smurf2 and IL- 4 in the curcumin group were lower than those in the paraquat group $(\mathrm{P}<0.05)$. In conclusion, curcumin can effectively improve pulmonary fibrosis in rats after treatment
\end{abstract}

Correspondence to: Dr Xiaoyan Fu, Department of Nursing, The First Hospital of Lanzhou University, 1 Donggang West Road, Lanzhou, Gansu 730000, P.R. China

E-mail: xs38ze@163.com

Key words: curcumin, paraquat poisoning, pulmonary fibrosis, rat model with paraquat poisoning. The results show that it is expected to be an effective drug for the treatment of paraquat, and provide effective reference and guidance for clinical treatment.

\section{Introduction}

Paraquat is a widely used non-selective herbicide, commonly used in agriculture (1). However, paraquat is also one of the herbicides mostly used for suicide. Paraquat has caused 20 deaths per million people worldwide, and the mortality rate is $60-70 \%(2,3)$. Paraquat poisoning toxicity involves multiple organs such as the digestive tract, skin and respiratory tract, which can lead to multiple organ dysfunction syndrome and renal failure (4). The main target organ of paraquat poisoning is the lung. In the later stage, the pulmonary alveolar and interstitial pulmonary fibrosis gradually occurred in patients. The reason of death is mostly due to respiratory failure caused by acute lung injury or acute respiratory distress syndrome in patients (5). Therefore, early diagnosis and early treatment are critical in patients with pulmonary fibrosis caused by paraquat poisoning. A large number of studies have found that curcumin is a phenolic pigment extracted from the underground rhizome of turmeric. It has antibacterial and anti-fibrotic pharmacological effects, and has become a major target of study in the medical field $(6,7)$.

Currently, the condition and prognosis of patients with paraquat poisoning are mostly determined by blood and urinary paraquat content. However, there is no agreed evaluation standard in the medical community for the time being, so the search for reliable prognostic factors will be helpful for clinical guidance in treatment (8). The blood gas index can directly reflect the air function of the lungs in the body, and is used to measure the gas and acid-base balance in the blood of the body. It is currently used as an indicator to observe whether the patient has symptoms such as hypoxemia, respiratory failure and coma (9). The Mothers against decapentaplegic homolog 4 (Smad4) is a transforming growth factor- $\beta 1$ (TGF- $\beta 1$ ) that transmits signals to the nucleus through specific receptors on the cell membrane (10). However, Smad ubiquitination regulatory factor2 (Smurf2) mediates the Smad signaling pathway and plays a pivotal role in the regulation of TGF- $\beta 1$ signaling 
activity $(11,12)$. Interferon- $\gamma($ IFN- $\gamma)$ is a Th-1 type cytokine that inhibits the proliferation of fibroblasts and promotes the degradation of fibroblasts, and has anti-pulmonary fibrosis (13). Interleukin-4 (IL-4) is a Th-2 type cytokine that promotes the proliferation of fibroblasts and also fibrosis through anti-apoptotic effects (14).

Currently, there are only a few clinical studies on the arterial blood gas index and the expression of Smad4, Smurf2, IL-4 and IFN- $\gamma$ in rats with pulmonary fibrosis induced by paraquat poisoning. Therefore, this study observed the rats with pulmonary fibrosis induced by paraquat poison, compared the changes of artery blood gas index and Smad4, Smurf2, IL-4 and IFN- $\gamma$ expression in rats with pulmonary fibrosis induced by curcumin.

\section{Materials and methods}

Animal data. A total of 54 clean 6-week-old Wistar rats weighing $224.24 \pm 4.36 \mathrm{~g}$ were purchased from the Experimental Center of Gansu University of traditional Chinese Medicine (production license no. SCXK 2012-0002; Gansu, China). The rats were raised at the temperature $24.00 \pm 2.00^{\circ} \mathrm{C}$, humidity $50.00 \pm 5.00 \%, 12 \mathrm{~h}$ day and night alternative, in normal single cages and free feeding and drinking water environment. This experiment was approved by the Ethics Committee of Gansu Provincial Hospital (Lanzhou, China).

Modeling. After feeding the rats for one week, 36 rats were randomly selected to model the lung fibrosis of paraquat poisoning. Paraquat (20\%) was diluted with distilled water 20 times to $0.2 \%$ paraquat (Beijing Bai Ao Si Biotechnology Co., Ltd., Beijing, China). The solution was configured with a concentration of $10 \mathrm{mg} / \mathrm{ml}$, and the rats were given a single oral gavage at $20 \mathrm{mg} / \mathrm{kg}$. There was no convulsion, death or vomiting during the intragastric administration. The pulmonary fibrosis was judged according to the rat lung diffusion function. The pulmonary fibrosis was determined according to the function of lung diffusion in rats. After $1 \mathrm{~h}$ of gavage, 18 rats were randomly selected to administer curcumin (Shanghai Baoman Bio-technology Co., Ltd., Shanghai, China) suspension of $200 \mathrm{mg} / \mathrm{kg}$ through intraperitoneal injection and classified as the curcumin group. The remaining 18 rats were given a saline injection of $10 \mathrm{ml} / \mathrm{kg}$ intraperitoneally and classified as the paraquat group. A further 18 rats were reared normally and were not processed, and classified as the control group.

Detection method. Rats in each group were randomly selected to obtain $0.5 \mathrm{ml}$ of venous blood on days 1 and 5 after modeling. After leaving the blood for $30 \mathrm{~min}$, the serum was separated by centrifugation at $3,000 \mathrm{x}$ g for $15 \mathrm{~min}$ at $4^{\circ} \mathrm{C}$, stored at $-20^{\circ} \mathrm{C}$ by using an enzyme-linked immunosorbent assay (ELISA) method. The following kits were used: rat SMAD4 ELISA kit (item no. H-EL-Smad4; ShanghaiZeye BiotechnologyCo.,Ltd.,Shanghai, China), rat Smurf2 ELISA kit (article no. wu-El082ra-s96; Shanghai Wuyi Biotechnology Co., Ltd., Shanghai, China), rat IL-4 ELISA kit (article no. RA20088; Wuhan Hualianke Biotechnology Co., Ltd., Wuhan, China), rat INF- $\gamma$ ELISA kit (article no. 865.010.048; Beijing Borede Biotechnology Co., Ltd., Beijing, China). The expression levels of Smad4, Smurf2, IL-4 and INF- $\gamma$ were measured in accordance with the operating instructions. Then, $0.5 \mathrm{ml}$ of abdominal aorta blood was drawn for the determination of $\mathrm{pH}$, arterial partial pressure of oxygen $\left(\mathrm{PaO}_{2}\right)$ and arterial partial pressure of carbon dioxide $\left(\mathrm{PaCO}_{2}\right)$ using a Thunder ABL80 blood gas analyzer (Nanjing Li Ai Trading Co., Ltd., Nanjing, China). After the blood was drawn, the rats were sacrificed by cervical dislocation.

Satistical analysis. The data were analyzed and processed by SPSS19.6 statistical software (Beijing Sitron Weida Information Technology Co., Ltd., Beijing, China). The results of the experiments were expressed as the mean \pm standard deviation. Multivariate time comparison was performed by repeated measures of ANOVA and the LSD post hoc test. A comparison between the two pairs was performed using a paired t-test. $\mathrm{P}<0.05$ was considered to indicate a statistically significant difference.

\section{Results}

Modeling results. In the 54 modeled rats, 53 were successfully modeled, and the modeling success rate was $98.15 \%$. There were 18 rats in the control group, 18 in the curcumin group, and 17 in the paraquat group.

Comparison of $\mathrm{pH}$ values of arterial whole blood in three groups of rats. The $\mathrm{pH}$ values of artery blood on days 1 and 5 in the curcumin group were $7.37 \pm 0.08$ and $7.39 \pm 0.06$, respectively. The $\mathrm{pH}$ values of artery blood on days 1 and 5 in the paraquat group were $7.40 \pm 0.04$ and $7.41 \pm 0.02$, respectively. The $\mathrm{pH}$ values of artery blood on days 1 and 5 in the control group were $7.37 \pm 0.06$ and $7.38 \pm 0.03$, respectively. There was no significant difference in the $\mathrm{pH}$ value of artery blood between days 1 and 5 in the curcumin group, the paraquat group or the control group ( $\mathrm{P}>0.05$; Fig. 1). On days 1 and 5 , the artery blood $\mathrm{pH}$ of the three groups was measured. There was no significant difference and it was not statistically significant $(\mathrm{P}>0.05)$.

Comparison of $\mathrm{PaO}_{2}$ in artery blood of rats between the three groups. The $\mathrm{PaO}_{2}$ of arterial blood on days 1 and 5 in the curcumin group was $83.75 \pm 13.65$ and $67.39 \pm 15.57 \mathrm{mmHg}$, respectively. The $\mathrm{PaO}_{2}$ of artery blood on days 1 and 5 in the paraquat group was $76.37 \pm 13.19$ and $50.40 \pm 16.53 \mathrm{mmHg}$, the artery blood $\mathrm{PaO}_{2}$ of the control group on days 1 and 5 was $89.65 \pm 16.43$ and $87.38 \pm 12.34 \mathrm{mmHg}$, respectively (Fig. 2).

The artery blood $\mathrm{PaO}_{2}$ of rats in the curcumin group was significantly higher on day 1 than day 5 , which was statistically significant $(\mathrm{t}=3.352, \mathrm{P}=0.002)$. The artery blood $\mathrm{PaO}_{2}$ of rats in the paraquat group was significantly higher on day 1 than that on day 5 , which was statistically significant $(\mathrm{t}=5.063, \mathrm{P}<0.001)$. There was no significant difference in $\mathrm{PaO}_{2}$ of artery blood on days 1 and 5 in the control group, which was not statistically significant $(\mathrm{P}>0.05)$. On days 1 and 5 , the artery blood $\mathrm{PaO}_{2}$ of rats in the three groups was statistically significant $(\mathrm{F}=3.666, \mathrm{P}=0.033 ; \mathrm{F}=27.080, \mathrm{P}<0.001)$ (data not shown). The artery blood $\mathrm{PaO}_{2}$ in the control group was higher than that in the curcumin and paraquat groups, and were statistically significant $(\mathrm{P}<0.05)$. The $\mathrm{PaO}_{2}$ of the artery blood in the curcumin group was higher than that in the paraquat group ( $\mathrm{P}<0.05$; Fig. 2$)$. 


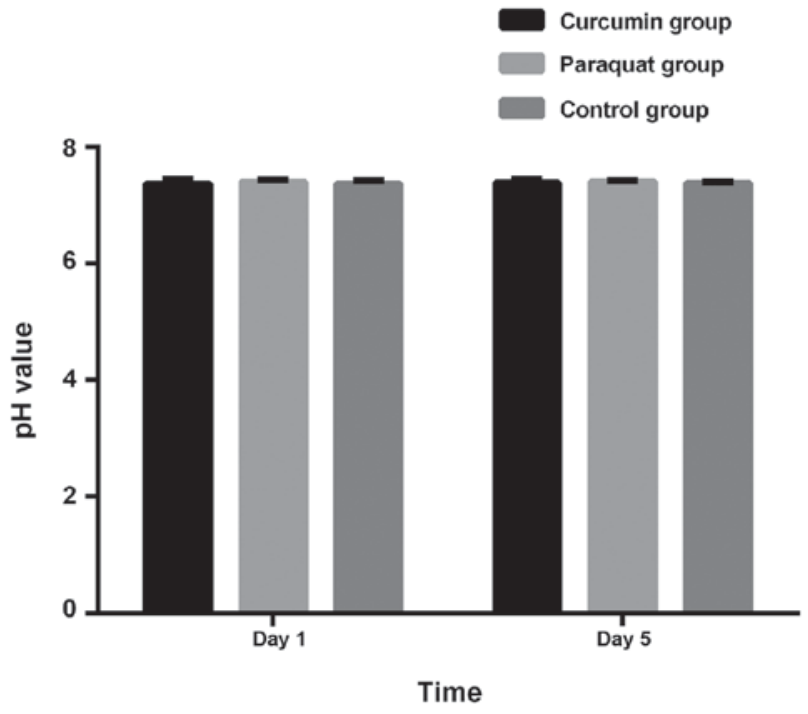

Figure 1. Comparison of artery blood $\mathrm{pH}$ values of rats between the three groups. The $\mathrm{pH}$ values of artery blood on days 1 and 5 in curcumin group were $7.37 \pm 0.08$ and $7.39 \pm 0.06$, respectively. The $\mathrm{pH}$ values of artery blood on days 1 and 5 in paraquat group were $7.40 \pm 0.04$ and $7.41 \pm 0.02$, respectively. The $\mathrm{pH}$ values of artery blood on days 1 and 5 in the control group were $7.37 \pm 0.06$ and $7.38 \pm 0.03$, respectively. There was no significant difference in the $\mathrm{pH}$ value of artery blood between days 1 and 5 in the curcumin group, the paraquat group and the control group $(\mathrm{P}>0.05)$. On days 1 and 5 , the artery blood $\mathrm{pH}$ values of the three groups was measured, and there was no significant difference and was not statistically significant $(P>0.05)$.

Comparison of $\mathrm{PaCO}_{2}$ values in artery blood of rats in the three groups. The $\mathrm{PaCO}_{2}$ of artery blood on days 1 and 5 in the curcumin group was $40.41 \pm 5.16$ and $53.73 \pm 5.72 \mathrm{mmHg}$, respectively. The $\mathrm{PaCO}_{2}$ of artery blood on days 1 and 5 in the paraquat group was $43.56 \pm 6.39$ and $69.67 \pm 6.53 \mathrm{mmHg}$, respectively. $\mathrm{PaCO}_{2}$ of artery blood on days 1 and 5 in the control group were $35.48 \pm 5.92$ and $36.54 \pm 5.61 \mathrm{mmHg}$, respectively (Fig. 3). The artery blood $\mathrm{PaCO}_{2}$ of rats in the curcumin group was significantly lower on day 1 than that on day 5 , which was statistically significant $(\mathrm{t}=4.230, \mathrm{P}<0.001)$. The artery blood $\mathrm{PaCO}_{2}$ of rats in the paraquat group was significantly lower on day 1 than that on day 5 , which was statistically significant $(\mathrm{t}=4.014, \mathrm{P}<0.001)$. There was no significant difference in $\mathrm{PaCO}_{2}$ between the control group on days 1 and 5, which was not statistically significant $(\mathrm{P}>0.05)$. On days 1 and 5 , the artery blood $\mathrm{PaCO}_{2}$ of rats in the three groups was statistically significant $(\mathrm{F}=8.366, \mathrm{P}<0.001 ; \mathrm{F}=26.030, \mathrm{P}<0.001)$ (data not shown). The arterial blood $\mathrm{PaCO}_{2}$ of the control group was lower than that in the curcumin and paraquat groups, which was statistically significant $(\mathrm{P}<0.05)$. The $\mathrm{PaCO}_{2}$ of artery blood in the curcumin group was lower than that in the paraquat group $(\mathrm{P}<0.05$; Fig. 3$)$.

Comparison of serum Smad4 values in rats between the three groups. The serum Smad4 of the curcumin group was lower on day 1 than that on day 5 , which was statistically significant $(t=2.260, P=0.030)$. The serum Smad4 of the paraquat group was significantly lower on day 1 than that on day 5 , which was statistically significant $(\mathrm{t}=5.223, \mathrm{P}<0.001)$; There was no significant difference in serum Smad4 between days 1 and 5 in the control $(\mathrm{P}>0.05)$. On days 1 and 5, the serum Smad4 of rats in the three group was statistically significant $(F=28.420$,

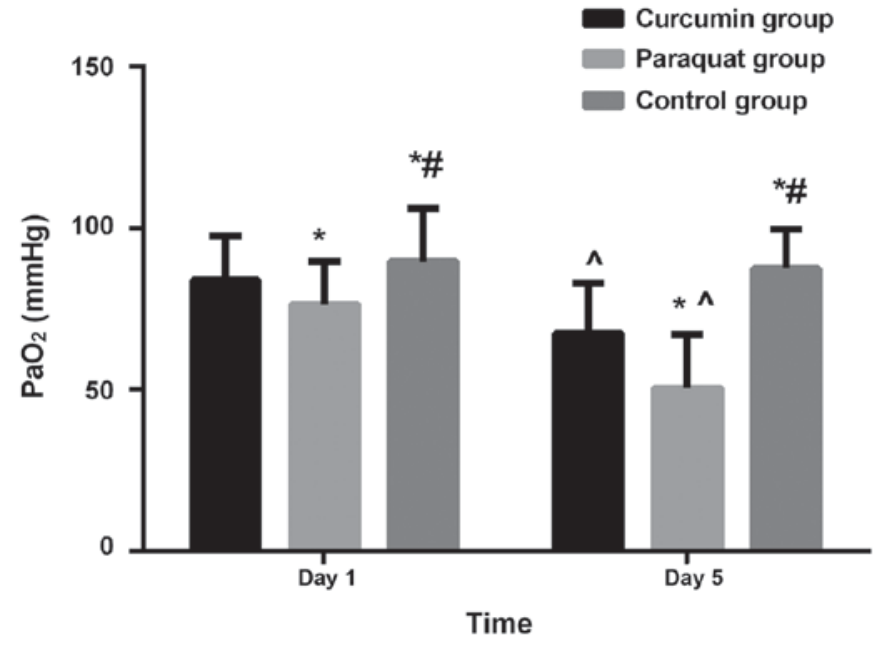

Figure 2. Comparison of $\mathrm{PaO}_{2}$ in artery blood of rats between the three groups. The $\mathrm{PaO}_{2}$ of artery blood on days 1 and 5 in the curcumin group was $83.75 \pm 13.65$ and $67.39 \pm 15.57 \mathrm{mmHg}$, respectively. The $\mathrm{PaO}_{2}$ of artery blood on days 1 and 5 in the paraquat group was $76.37 \pm 13.19$ and $50.40 \pm 16.53$ $\mathrm{mmHg}$, respectively, the artery blood $\mathrm{PaO}_{2}$ of the control group on days 1 and 5 were $89.65 \pm 16.43$ and $87.38 \pm 12.34 \mathrm{mmHg}$, respectively. $\mathrm{PaO}_{2}$ in artery blood of rats in the curcumin group on day 1 was significantly higher than that on day 5 , which was statistically significant $(\mathrm{P}<0.05) . \mathrm{PaO}_{2}$ in artery blood of rats in the paraquat group was significantly higher on day 1 than that on day 5 , which was statistically significant $(\mathrm{P}<0.001)$. There was no significant difference in $\mathrm{PaO}_{2}$ of artery blood on days 1 and 5 in the control group, which was not statistically significant $(\mathrm{P}>0.05)$. On days 1 and 5, $\mathrm{PaO}_{2}$ in the artery blood of rats between the three groups was statistically significant $(\mathrm{P}<0.001)$. The artery blood $\mathrm{PaO}_{2}$ of the control group was higher than that in the curcumin group and paraquat group, which were statistically significant $(\mathrm{P}<0.05)$. The $\mathrm{PaO}_{2}$ of artery blood in the curcumin group was higher than that in the paraquat group, which was statistically significant $(\mathrm{P}<0.05)$. ${ }^{*} \mathrm{P}<0.05$, when compared with the curcumin group; ${ }^{\text {"}} \mathrm{P}<0.05$, when compared with the paraquat group and ${ }^{\wedge} \mathrm{P}<0.05$, when compared to day 1 .

$\mathrm{P}<0.001 ; \mathrm{F}=92.180, \mathrm{P}<0.001)$. The serum Smad4 of rats in the control group was significantly lower than that in the curcumin and paraquat group $(\mathrm{P}<0.05)$. The serum Smad4 in the curcumin group was lower than that in the paraquat group $(\mathrm{P}<0.05$; Table I).

Comparison of serum Smurf2 values of rats in the three groups. The serum Smurf2 of the curcumin group was lower on day 1 than that on day 5 , which was statistically significant $(t=5.188, P<0.001)$. The serum Smurf2 of the paraquat group was significantly lower on day 1 than that on day 5 , which was statistically significant $(\mathrm{t}=4.786, \mathrm{P}<0.001)$; There was no significant difference in serum Smurf2 between the control group on days 1 and $5(\mathrm{P}>0.05)$. On days 1 and 5 , the serum Smurf2 of rats between the three groups was statistically significant $(\mathrm{F}=66.480, \mathrm{P}<0.001 ; \mathrm{F}=135.000, \mathrm{P}<0.001)$. Serum Smurf2 in the control group was significantly lower than that in the curcumin and paraquat groups $(\mathrm{P}<0.05)$. Serum Smurf2 in the curcumin group was lower than that in the paraquat group $(\mathrm{P}<0.05$; Table II).

Comparison of serum IL-4 in rats in the three groups. Serum IL-4 in the curcumin group was lower on day 1 than that on day 5 , which was statistically significant $(\mathrm{t}=4.749, \mathrm{P}<0.001)$. The serum IL-4 level in the paraquat group was significantly lower on day 1 than that on day 5 , which was statistically 
Table I. Comparison of serum Smad4 values in rats between the three groups (pg/ml).

\begin{tabular}{lccr}
\hline Groups & Day 1 & Day 5 & t \\
\hline Curcumin group $(\mathrm{n}=18)$ & $58.45 \pm 12.36$ & $67.35 \pm 11.24$ & 2.260 \\
Paraquat group $(\mathrm{n}=17)$ & $75.27 \pm 13.73^{\mathrm{a}}$ & $100.92 \pm 14.88^{\mathrm{a}}$ & 5.223 \\
Control group $(\mathrm{n}=18)$ & $44.73 \pm 9.62^{\mathrm{a}, \mathrm{b}}$ & $45.19 \pm 10.15^{\mathrm{a}, \mathrm{b}}$ & 0.140 \\
F & 28.420 & 92.180 & 0.001 \\
P-value & $<0.001$ & $<0.001$ & \\
\hline
\end{tabular}

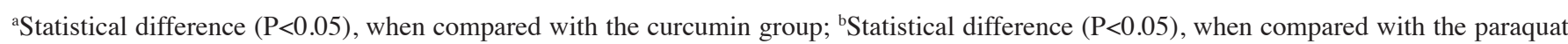
group.

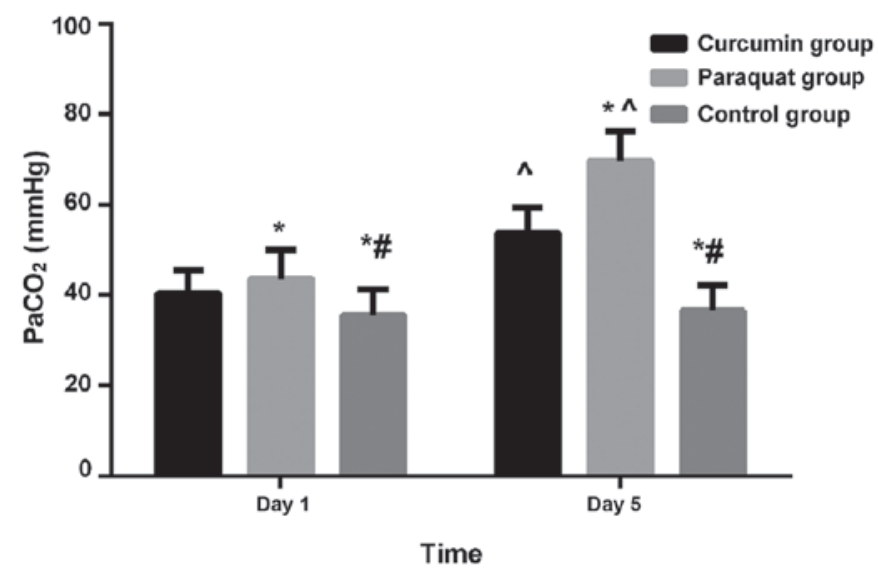

Figure 3. Comparison of artery blood $\mathrm{PaCO}_{2}$ values of rats between the three groups. The $\mathrm{PaCO}_{2}$ of artery whole blood on days 1 and 5 in the curcumin group were $40.41 \pm 5.16 \mathrm{mmHg}$ and $53.73 \pm 5.72 \mathrm{mmHg}$, respectively. The $\mathrm{PaCO}_{2}$ of artery blood on days 1 and 5 in the paraquat group was $43.56 \pm 6.39$ $\mathrm{mmHg}$ and $69.67 \pm 6.53 \mathrm{mmHg}$, respectively. The $\mathrm{PaCO}_{2}$ of artery blood days 1 and 5 in the control group was $35.48 \pm 5.92 \mathrm{mmHg}$ and $36.54 \pm 5.61$ $\mathrm{mmHg}$, respectively. $\mathrm{PaCO}_{2}$ in artery blood of rats in the curcumin group was significantly lower on day 1 than that on day 5 , which was statistically significant $(\mathrm{P}<0.001) . \mathrm{PaCO}_{2}$ in artery blood of rats in the paraquat group was significantly lower on day 1 than that on day 5 , which was statistically significant $(\mathrm{P}<0.001)$; There was no significant difference in $\mathrm{PaCO}_{2}$ on days 1 and 5 in the control group, which was not statistically significant $(\mathrm{P}>0.05)$. On days 1 and 5 , the artery blood $\mathrm{PaCO}_{2}$ of rats between the three groups was statistically significant $(\mathrm{P}<0.001)$; The artery blood $\mathrm{PaCO}_{2}$ of the control group was lower than that in the curcumin group and paraquat group, which were statistically significant $(\mathrm{P}<0.05)$. The $\mathrm{PaCO}_{2}$ of artery blood in the curcumin group was lower than that in the paraquat group, which was statistically significant $(\mathrm{P}<0.05)$. ${ }^{*} \mathrm{P}<0.05$, when compared with the curcumin group; ${ }^{\text {}} \mathrm{P}<0.05$, when compared with the paraquat group and ${ }^{\wedge} \mathrm{P}<0.05$, compared to day 1 .

significant $(\mathrm{t}=6.248, \mathrm{P}<0.001)$. There was no significant difference in serum IL-4 between days 1 and 5 in the control group, which was not statistically significant $(\mathrm{P}>0.05)$. On days 1 and 5, serum IL-4 of rats in the three groups was statistically significant $(\mathrm{F}=202.200, \mathrm{P}<0.001 ; \mathrm{F}=330.400$, $\mathrm{P}<0.001)$. Serum IL-4 in the control group was significantly lower than that in the curcumin group and the paraquat group $(\mathrm{P}<0.05)$. Serum IL-4 was lower in the curcumin group than that in the paraquat group, which was statistically significant $(\mathrm{P}<0.05$; Table III).

Comparison of serum INF- $\gamma$ in rats between the three groups. Serum INF- $\gamma$ in the curcumin group was significantly higher on day 1 than that on day 5 , which was statistically significant $(\mathrm{t}=5.959, \mathrm{P}<0.001)$. The serum INF- $\gamma$ in the paraquat group was significantly higher on day 1 than that on day 5 , which was statistically significant $(\mathrm{t}=4.118, \mathrm{P}<0.001)$; there was no significant difference in serum INF- $\gamma$ between days 1 and 5 in the control group, which was not statistically significant (P>0.05). On days 1 and 5, serum INF- $\gamma$ of rats in the three groups was statistically significant $(\mathrm{F}=9.138, \mathrm{P}<0.001$; $\mathrm{F}=26.030, \mathrm{P}<0.001)$. The serum INF- $\gamma$ of the control group was significantly higher than that in the curcumin group and the paraquat group $(\mathrm{P}<0.05)$. The serum $I N F-\gamma$ of the curcumin group was higher than that in the paraquat group, which was statistically significant $(\mathrm{P}<0.05$; Table IV).

\section{Discussion}

Pulmonary fibrosis caused by paraquat is a chronic progressive inflammatory disease that can cause diffuse alveolitis and alveolar structural disorders. However, due to the lack of effective treatment methods, the mortality rate remains high and seriously endangers the life and health of patients (15). In recent years, it has been reported that curcumin can inhibit the transformation of epithelial to mesenchymal, and has anti-angiogenic, pro-apoptotic and immunomodulatory effects, which can inhibit the occurrence and development of tumors and make curcumin a focus of research $(16,17)$. Curcumin has the characteristics of large safe concentration of drug, small adverse reaction and low price, and has been widely used in the treatment of many diseases, such as colorectal cancer, lung cancer and inflammatory diseases (18-20). Therefore, this study investigated the effects of curcumin on a rat model of pulmonary fibrosis induced by paraquat.

In this study, we found that the $\mathrm{PaO}_{2}$ in the artery blood of the curcumin group was higher than that in the paraquat group, the $\mathrm{PaCO}_{2}$ was lower than that in the paraquat group. The $\mathrm{PaO}_{2}$ and $\mathrm{PaCO}_{2}$ levels can be used to determine whether a patient has symptoms such as $\mathrm{CO}_{2}$ retention and hypoxia, and can reflect the degree or type of respiratory disease of the patient (21). Due to the massive replacement of alveolar fibrosis in the absence of gas exchange function in pulmonary fibrosis, normal lung tissue structure degeneration and partial lung function loss, $\mathrm{CO}_{2}$ retention may occur in the blood, which may lead to poor breathing, hypoxia, and can even lead to death of the patient (22). According to studies reported by Lelli et al (23), curcumin has a variety of pro-growth effects, 
Table II. Comparison of serum Smurf2 values in rats between the three groups (pg/ml).

\begin{tabular}{lccr}
\hline Groups & Day 1 & Day 5 & t \\
\hline Curcumin group $(\mathrm{n}=18)$ & $53.41 \pm 8.72$ & $68.83 \pm 9.11$ & 5.188 \\
Paraquat group $(\mathrm{n}=17)$ & $64.55 \pm 9.28^{\mathrm{a}}$ & $81.56 \pm 11.34^{\mathrm{a}}$ & 4.786 \\
Control group $(\mathrm{n}=18)$ & $31.62 \pm 7.84^{\mathrm{a}, \mathrm{b}}$ & $30.77 \pm 8.05^{\mathrm{a}, \mathrm{b}}$ & $<.001$ \\
F & 66.480 & 135.000 & 0.321 \\
P-value & $<0.001$ & $<0.001$ & 0.750 \\
\end{tabular}

Statistical difference $(\mathrm{P}<0.05)$, when compared with the ${ }^{\mathrm{a}}$ curcumin and ${ }^{\mathrm{b}}$ paraquat groups.

Table III. Comparison of serum IL-4 values of rats between the three groups (ng/l).

\begin{tabular}{lccr}
\hline Groups & Day 1 & Day 5 & t \\
\hline Curcumin group $(\mathrm{n}=18)$ & $262.73 \pm 9.81$ & $278.54 \pm 10.16$ & 4.749 \\
Paraquat group $(\mathrm{n}=17)$ & $284.49 \pm 10.72^{\mathrm{a}}$ & $308.48 \pm 11.65^{\mathrm{a}}$ & 6.248 \\
Control group $(\mathrm{n}=18)$ & $221.52 \pm 7.58^{\mathrm{a}, \mathrm{b}}$ & $222.69 \pm 8.13^{\mathrm{a}, \mathrm{b}}$ & 0.447 \\
F & 202.200 & 330.400 & $<0.001$ \\
P-value & $<0.001$ & $<0.001$ & 0.658 \\
\hline
\end{tabular}

Statistical difference $(\mathrm{P}<0.05)$, when compared with the ${ }^{\mathrm{a}}$ curcumin and ${ }^{\mathrm{b}}$ paraquat groups.

Table IV. Comparison of serum INF- $\gamma$ values of rats between the three groups (ng/l).

\begin{tabular}{|c|c|c|c|c|}
\hline Groups & Day 1 & Day 5 & $\mathrm{t}$ & P-value \\
\hline Curcumin group $(n=18)$ & $528.91 \pm 18.42$ & $491.66 \pm 19.08$ & 5.959 & $<0.001$ \\
\hline Paraquat group $(\mathrm{n}=17)$ & $473.15 \pm 19.86^{\mathrm{a}}$ & $445.95 \pm 18.63^{\mathrm{a}}$ & 4.118 & $<0.001$ \\
\hline Control group $(n=18)$ & $580.62 \pm 20.75^{\mathrm{a}, \mathrm{b}}$ & $577.36 \pm 18.28^{\mathrm{a}, \mathrm{b}}$ & 0.500 & 0.620 \\
\hline $\mathrm{F}$ & 9.138 & 26.030 & & \\
\hline P-value & $<0.001$ & $<0.001$ & & \\
\hline
\end{tabular}

Statistical difference $(\mathrm{P}<0.05)$, when compared with the acurcumin and ${ }^{\mathrm{b}}$ paraquat groups.

which may play a role in the treatment of lung diseases such as lung cancer, as well as the regulation of transcription factors, cytokines, adhesion molecules and enzymes that play a key role in inflammation and cancer. Therefore, rats with pulmonary fibrosis caused by paraquat poisoning had lower $\mathrm{PaO}_{2}$ and higher $\mathrm{PaCO}_{2}$ than normal rats. When paraquat-poisoned rats were treated with curcumin, their blood gas indexes were normal compared with those in the paraquat group. Recent studies have found that curcumin has an obvious anti-pulmonary fibrosis effect, and its conclusions can be used to support our research (24). In recent years, it has been reported that TGF- $\beta$ plays a key role in the development and progression of pulmonary fibrosis, and TGF- $\beta 1$ causes pulmonary fibrosis by promoting the proliferation, invasion and activation of lung fibroblasts (25). Smurfs plays a pivotal role in the regulation of TGF- $\beta 1$ signaling by selectively mediating the degradation of key components in the Smad signaling pathway, and its dysfunction leads to abnormal TGF- $\beta 1 /$ Smads signaling and to a series of pathophysiological changes. It has been reported that Smad4 and Smurf2 can promote the development of pulmonary fibroblasts in pulmonary fibrosis $(26,27)$. Furthermore, they have a key role in pulmonary fibrosis, which is in agreement with our research results. The report of Yallapu et al (28), indicates that curcumin inhibits the synthesis of extracellular matrix and inhibits collagen synthesis through Smad-mediated signaling pathway, thereby reducing cardiac repair and improving cardiac function after ischemia-reperfusion. It was found that curcumin can reduce myocardial ischemia and fibrosis as well as significantly downregulated the expression of TGF- $\beta 1$ and Smad in ischemia-reperfusion myocardium (28). Furthermore, curcumin, not only reduced myocardial ischemia and fibrosis, but significantly downregulated the expression of TGF- $\beta 1$ and Smad in ischemia-reperfusion myocardium (28). Those findings may support our research results. When the stress response is repaired after the lung is damaged, IFN- $\gamma$ can inhibit the activation and proliferation of fibroblasts and promote the synthesis of collagen (29). The 
expression of TGF- $\beta 1$ and Smad in ischemia-reperfusion myocardium were also significantly downregulated, which may support our findings. When lung damage occurs and stress response is repaired, IFN- $\gamma$ can inhibit the activation and proliferation of fibroblasts and promote collagen synthesis (29). IL-4 can induce fibroblast proliferation and promote exogenous collagen to cause fibrosis, which accumulates in the lungs and causes lung damage through oxidation and inflammation processes (30). When the body is normal, IFN- $\gamma$ and IL-4 are in a state of equilibrium, which plays a key regulatory role in the body's immune response. However, fibrosis occurs when IL-4 is transferred. According to the in vitro studies of LITERAT (31), curcumin can inhibit the production of alveolar inflammatory cytokines IL- $\beta 1$ and IL-8. In addition, the nasal administration of curcumin can inhibit airway inflammation and pulmonary fibrosis (32), which further validates our experiment.

Further aspects remain to be explored, including the mechanism influence of curcumin on paraquat poisoning. Of note, differences between animal models and human body should be considered. Consequently, experiments regarding the effect of curcumin on paraquat poisoning in human are to be conducted in future studies.

In summary, curcumin can effectively improve pulmonary fibrosis in rats after treatment of paraquat poisoning. In addition, it is expected to be an effective drug for treating paraquat and providing effective reference and guidance for clinical treatment.

\section{Acknowledgements}

Not applicable.

\section{Funding}

This study was supported by Lanzhou Health Science and Technology Development Project (no. LZWSKY2014-2-18).

\section{Availability of data and materials}

The datasets used and/or analyzed during the present study are available from the corresponding author on reasonable request.

\section{Authors' contributions}

$\mathrm{HC}$ wrote the manuscript. $\mathrm{HC}$ and $\mathrm{XF}$ were responsible for construction of the lung fibrosis model. HC and RY performed ELISA. RY and YT helped with determination of $\mathrm{pH}, \mathrm{PaO}_{2}$ and $\mathrm{PaCO}_{2}$. All authors read and approved the final manuscript.

\section{Ethics approval and consent to participate}

The study was approved by the Ethics Committee of Gansu Provincial Hospital (Lanzhou, China).

\section{Patient consent for publication}

Not applicable.

\section{Competing interests}

The authors declare that they have no competing interests.

\section{References}

1. Rasooli R, Rajaian H, Pardakhty A and Mandegary A: Preference of aerosolized pirfenidone to oral intake: an experimental model of pulmonary fibrosis by paraquat. J Aerosol Med Pulm Drug Deliv 31: 25-32, 2018.

2. Kim HJ, Kim HK, Lee H, Bae JS, Kown JT, Gil HW and Hong SY: Toxicokinetics of paraquat in Korean patients with acute poisoning. Korean J Physiol Pharmacol 20: 35-39, 2016.

3. Bromilow RH: Paraquat and sustainable agriculture. Pest Manag Sci 60: 340-349, 2004

4. Wen C, Wang Z, Zhang M, Wang S, Geng P, Sun F, Chen M, Lin G, Hu L, Ma J, et al: Metabolic changes in rat urine after acute paraquat poisoning and discriminated by support vector machine. Biomed Chromatogr 30: 75-80, 2016.

5. Khalighi Z, Rahmani A, Cheraghi J,Ahmadi MR, Soleimannejad K, Asadollahi R and Asadollahi K: Perfluorocarbon attenuates inflammatory cytokines, oxidative stress and histopathologic changes in paraquat-induced acute lung injury in rats. Environ Toxicol Pharmacol 42: 9-15, 2016.

6. Gunes H, Gulen D, Mutlu R, Gumus A, Tas T and Topkaya AE: Antibacterial effects of curcumin: An in vitro minimum inhibitory concentration study. Toxicol Ind Health 32: 246-250, 2016.

7. Xiao J, Sheng X, Zhang X, Guo M and Ji X: Curcumin protects against myocardial infarction-induced cardiac fibrosis via SIRT1 activation in vivo and in vitro. Drug Des Devel Ther 10: 1267-1277, 2016.

8. Wang HR, Pan J, Shang AD and Lu YQ: Time-dependent haemoperfusion after acute paraquat poisoning. Sci Rep 7: 2239, 2017.

9. Huang R and Li M: Protective effect of Astragaloside IV against sepsis-induced acute lung injury in rats. Saudi Pharm J 24: 341-347, 2016.

10. Zandvoort A, Postma DS, Jonker MR, Noordhoek JA, Vos JT and Timens W: Smad gene expression in pulmonary fibroblasts: indications for defective ECM repair in COPD. Respir Res 16: 83, 2008.

11. Cai Y, Zhou CH, Fu D and Shen XZ: Overexpression of Smad ubiquitin regulatory factor 2 suppresses transforming growth factor- $\beta$ mediated liver fibrosis. J Dig Dis 13: 327-334, 2012.

12. Nakano A, Koinuma D, Miyazawa K, Uchida T, Saitoh M, Kawabata M, Hanai J, Akiyama H, Abe M, Miyazono K, et al: Pin1 down-regulates transforming growth factor-beta (TGF-beta) signaling by inducing degradation of Smad proteins. J Biol Chem 284: 6109-6115, 2009.

13. Ziesche R and Block LH: Mechanisms of antifibrotic action of interferon gamma-1b in pulmonary fibrosis. Wien Klin Wochenschr 112: 785-790, 2000.

14. Kodera T, McGaha TL, Phelps R, Paul WE and Bona CA: Disrupting the IL-4 gene rescues mice homozygous for the tight-skin mutation from embryonic death and diminishes TGF-beta production by fibroblasts. Proc Natl Acad Sci USA 99: 3800-3805, 2002.

15. Javad-Mousavi SA, Hemmati AA, Mehrzadi S, Hosseinzadeh A, Houshmand G, Rashidi Nooshabadi MR, Mehrabani M and Goudarzi M: Protective effect of Berberis vulgaris fruit extract against Paraquat-induced pulmonary fibrosis in rats. Biomed Pharmacother 81: 329-336, 2016.

16. Mirzaei H, Naseri G, Rezaee R, Mohammadi M, Banikazemi Z, Mirzaei HR, Salehi H, Peyvandi M, Pawelek JM and Sahebkar A: Curcumin: A new candidate for melanoma therapy? Int J Cancer 139: 1683-1695, 2016.

17. Mirzaei H, Khoi MJ, Azizi M and Goodarzi M: Can curcumin and its analogs be a new treatment option in cancer therapy? Cancer Gene Ther 23: 410, 2016.

18. Mudduluru G, George-William JN, Muppala S, Asangani IA, Kumarswamy R, Nelson LD and Allgayer H: Curcumin regulates miR-21 expression and inhibits invasion and metastasis in colorectal cancer. Biosci Rep 31: 185-197, 2011.

19. Chin KY: The spice for joint inflammation: Anti-inflammatory role of curcumin in treating osteoarthritis. Drug Des Devel Ther 10: 3029-3042, 2016. 
20. Ting CY, Wang HE, Yu CC, Liu HC, Liu YC and Chiang IT: Curcumin triggers DNA damage and inhibits expression of DNA repair proteins in human lung cancer cells. Anticancer Res 35: 3867-3873, 2015.

21. Spindelboeck W, Gemes G, Strasser C, Toescher K, Kores B, Metnitz P, Haas J and Prause G: Arterial blood gases during and their dynamic changes after cardiopulmonary resuscitation: A prospective clinical study. Resuscitation 106: 24-29, 2016.

22. Campo G, Pavasini R, Malagù M, Mascetti S, Biscaglia S, Ceconi C, Papi A and Contoli M: Chronic obstructive pulmonary disease and ischemic heart disease comorbidity: Overview of mechanisms and clinical management. Cardiovasc Drugs Ther 29: 147-157, 2015.

23. Lelli D, Sahebkar A, Johnston TP and Pedone C: Curcumin use in pulmonary diseases: State of the art and future perspectives. Pharmacol Res 115: 133-148, 2017.

24. Punithavathi D, Venkatesan N and Babu M: Protective effects of curcumin against amiodarone-induced pulmonary fibrosis in rats. Br J Pharmacol 139: 1342-1350, 2003.

25. Richter $\mathrm{K}$ and Kietzmann T: Reactive oxygen species and fibrosis: Further evidence of a significant liaison. Cell Tissue Res 365: 591-605, 2016.

26. Li YJ, Azuma A, Usuki J, Abe S, Matsuda K, Sunazuka T, Shimizu T, Hirata Y, Inagaki H, Kawada T, et al: EM703 improves bleomycin-induced pulmonary fibrosis in mice by the inhibition of TGF-beta signaling in lung fibroblasts. Respir Res 7: 16, 2006.

27. Bellaye PS, Wettstein G, Burgy O, Besnard V, Joannes A, Colas J, Causse S, Marchal-Somme J, Fabre A, Crestani B, et al: The small heat-shock protein $\alpha \mathrm{B}$-crystallin is essential for the nuclear localization of Smad4: Impact on pulmonary fibrosis J Pathol 232: 458-472, 2014.
28. Yallapu MM, Jaggi M and Chauhan SC: Curcumin nanoformulations: A future nanomedicine for cancer. Drug Discov Today 17: 71-80, 2012.

29. Midgley AC, Morris G, Phillips AO and Steadman R: $17 \beta$-estradiol ameliorates age-associated loss of fibroblast function by attenuating IFN- $\gamma / \mathrm{STAT} 1-$ dependent miR-7 upregulation. Aging Cell 15: 531-541, 2016.

30. Amirshahrokhi $\mathrm{K}$ and Khalili AR: Carvedilol attenuates paraquat-induced lung injury by inhibition of proinflammatory cytokines, chemokine MCP-1, NF- $\kappa$ B activation and oxidative stress mediators. Cytokine 88: 144-153, 2016.

31. Literat A, Su F, Norwicki M, Durand M, Ramanathan R, Jones CA, Minoo P and Kwong KY: Regulation of pro-inflammatory cytokine expression by curcumin in hyaline membrane disease (HMD). Life Sci 70: 253-267, 2001.

32. Chauhan PS, Dash D and Singh R: Intranasal curcumin inhibits pulmonary fibrosis by modulating matrix metalloproteinase-9 (MMP-9) in ovalbumin-induced chronic asthma. Inflammation 40: 248-258, 2017.

This work is licensed under a Creative Commons Attribution-NonCommercial-NoDerivatives 4.0 International (CC BY-NC-ND 4.0) License. 